\title{
(RE) CONSTRUÇÃO DE PERCURSOS FORMATIVOS AO LONGO DA VIDA: O CASO DOS CURSOS DE EDUCAÇÃO E FORMAÇÃO DE ADULTOS (EFA) ${ }^{1}$
}

\author{
Lurdes Pratas Nico, Ana Paula Romão, Natália Galego, \\ Rui Gusmão, Manuela Roque \& Susana Ramalho
}

\section{Enquadramento}

Nos dias 19 e 20 de Novembro, a Equipa de Projecto Novas Oportunidades de Adultos (EPNOA), participou na VI Edição do Encontro Regional "Aprender no Alentejo", no qual apresentou uma comunicação intitulada (re)Construção de percursos formativos ao longo da vida: o caso dos Cursos de Educação e Formação de Adultos (EFA).

Os Cursos de Educação e Formação de Adultos (adiante designados Cursos EFA), assumemse como uma das respostas formativas e de qualificação disponíveis no sistema de educação e de qualificação em Portugal. Desde a sua criação, até à data, ocorreram alterações várias, sob o ponto de vista legal, metodológico e pedagógico. Procurou-se efectuar uma breve descrição da oferta EFA, apontando-se duas dimensões: (i) a sua génese e evolução; (ii) as especificidades do seu modelo de formação/ estrutura curricular, relacionando essas dimensões com a importância do princípio de Aprendizagem ao Longo da Vida (ALV). Como palavras-chave destaque para educação e formação de adultos e aprendizagem ao longo da vida.

No seguimento da Cimeira de Lisboa, foi lançado o Memorando sobre a Aprendizagem ao Longo da Vida (Comissão Europeia, 2000), com base num trabalho prévio de consulta à escala europeia. O objectivo final foi implementar um conjunto de medidas e acções conducentes à aprendizagem ao longo da vida em toda a Europa. No Memorando são apresentadas seis mensagens-chave, das quais, se destacamos duas: (1) Valorizar a aprendizagem; (2) Aproximar a aprendizagem dos indivíduos, no sentido das respostas formativas responderem às necessidades $\mathrm{e}$ circunstâncias dos indivíduos, numa perspectiva de formação contínua e de actualização de competências (Nico, 2009:68).

\section{A génese e evolução dos Cursos EFA}

Os cursos EFA são um instrumento basilar para a prossecução das actuais políticas de educação e formação, assumindo particular destaque na generalização do nível secundário

\footnotetext{
${ }^{1}$ Equipa de Projecto Novas Oportunidades de Adultos (EP-NOA). Esta equipa foi criada, por despacho interno, da Direcção Regional de Educação do Alentejo (DREALE), em Setembro de 2006. Como missão, assume o acompanhamento da implementação das orientações de política educativa e formativa, junto dos estabelecimentos de ensino, agrupamentos e instituições públicas e privadas na área da Educação e Formação de Adultos e promove, também, a criação e o reforço de redes de aprendizagem, envolvendo as comunidades e as respectivas instituições. Mais informação disponível em http://novasoportunidades.drealentejo.pt E-mail de contacto: novas.oportunidades@drealentejo.pt
} 
com patamar mínimo de qualificação da população. Na sua génese, os cursos EFA são um instrumento de qualificação da população adulta, contribuindo, assim, para a promoção de uma cidadania mais activa e para a melhoria dos níveis de empregabilidade e inclusão social e profissional.

Em 1998, foi constituído um Grupo de Missão para o Desenvolvimento da Educação e Formação de Adultos (GMEFA) através da Resolução do Conselho de Ministros n. -92/98, de 14 de Julho, e incumbido, desde logo, de desencadear o processo conducente à constituição da Agência Nacional de Educação e Formação de Adultos (ANEFA). Em 28 de Setembro de 1999, através do Decreto-Lei $n .{ }^{0}$ 387/99, é criada a Agência Nacional de Educação e Formação de Adultos (ANEFA), sendo-lhe atribuída múltiplas atribuições ${ }^{2}$ (Nico, 2009:172). No âmbito das medidas inovadoras trazidas pela ANEFA, Nico (2009:176-185), destaca três: os primeiros Cursos de Educação e Formação de Adultos, as Acções S@Ber $+{ }^{3} \mathrm{e}$ o Sistema de Reconhecimento, Validação e Certificação de Competências.

Os cursos EFA representaram uma ruptura inequívoca com os modelos de educação e formação de adultos, até então existentes na sociedade portuguesa. Em 2000, Regulamentados pelo Despacho Conjunto ํㅜ 1083 /2000, de 20 de Novembro, os cursos EFA pretendiam atingir os seguintes objectivos:

1. Proporcionar uma oferta integrada de educação de educação e formação destinada a públicos adultos maiores de 18 anos, pouco qualificados;

2. Contribuir para a redução do défice de qualificação escolar e profissional doa população portuguesa, potenciando as suas condições de empregabilidade;

3. Promover a construção de uma rede local de EFA;

4. Constitui-se como um campo de aplicação de um modelo inovador de educação e formação de adultos.

De acordo com o Relatório Nacional sobre os Cursos de Educação e Formação de Adultos "Em Observação" - 2000 - 2001 (ANEFA, 2002), a rede inicial de cursos EFA foi constituída por 13 cursos, a nível nacional, dois dos quais na região Alentejo. Um foi promovido pela entidade Esdime (Agência para o Desenvolvimento Local no Alentejo Sudoeste, CRL, sedeada em Ferreira do Alentejo) ${ }^{4}$ e o outro pelo Centro de Formação Profissional de Santiago do Cacém $^{5}$ (ANEFA, 2002:69). A ESDIME foi, depois, também entidade piloto no âmbito dos Centros de RVCC, em 2001. Um dos critérios de selecção foi a experiência adquirida no âmbito destes Cursos EFA (Nico, 2009:177).

\footnotetext{
${ }^{2}$ A ANEFA foi extinta em 2002, tendo sido criada a Direcção-Geral de Formação Vocacional (DGFV, 2002-2006). Actualmente é a Agência Nacional para a Qualificação (ANQ, I.P.) que gere e monitoriza a rede de Cursos EFA e a rede de Centros Novas Oportunidades, disseminadas por todo o país.

${ }^{3}$ As acções S@Ber + constituíram acções de curta duração promovidas pela ANEFA e por diversas instituições públicas e privadas, cujo objectivo consistiu em "motivar a população adulta a melhorar as suas qualificações escolares ou profissionais." (Trigo, 2001:27).

${ }_{5}^{4}$ Curso EFA B2 de Práticas Administrativas.

${ }^{5}$ Curso EFA B1 de Agricultura e Pescas - Jardinagem.
} 
Em 2006, as escolas da rede pública começaram a desenvolver cursos EFA, de forma generalizada, e foram introduzidos os cursos EFA, apenas com a vertente escolar, o que constituiu uma valorização da oferta, através da Iniciativa Novas Oportunidades. Nesse mesmo ano, com a publicação do Referencial de Competências-Chave para a Educação e Formação de Adultos de Nível Secundário, permitiu-se o desenvolvimento de cursos EFA de Nível Secundário.

Actualmente, a rede de Cursos EFA, inscreve-se numa rede alargada em termos de públicos (não apenas para os públicos mais desfavorecidos, carenciados, mas também para os activos empregados), aumentou o número de cursos em funcionamento e de entidades promotoras, com um crescimento, ainda, mais visível por parte das escolas públicas do Ministério da Educação (Nico, 2009:177).

De 2000 até 2010, na região Alentejo, a rede de cursos evoluiu, de modo significativo, como se pode observar no gráfico em baixo:

\section{Gráfico 1. Evolução da Rede de Cursos EFA na região Alentejo (período 2000-2010)}

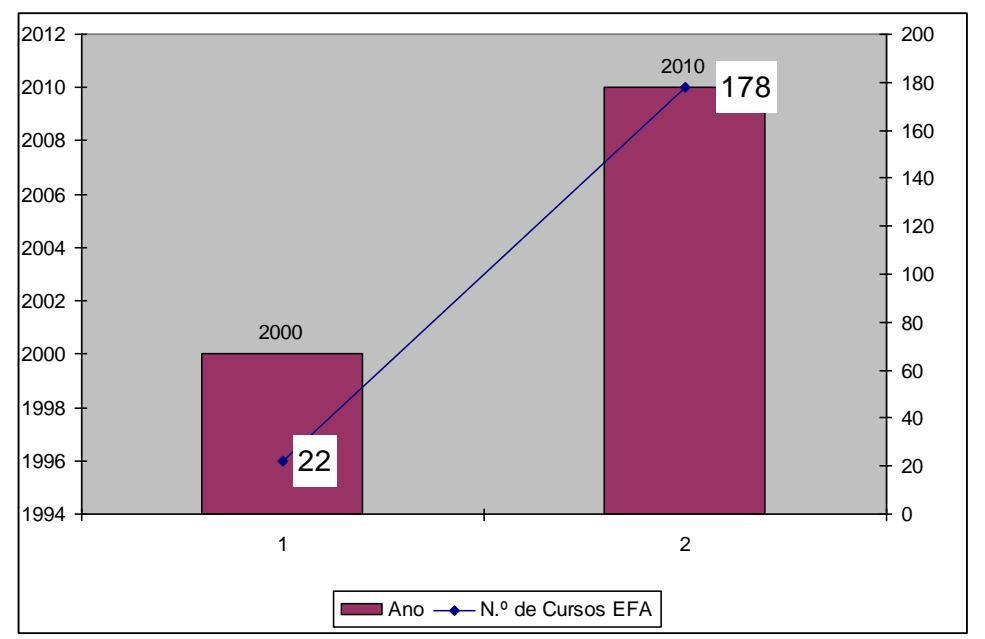

Fonte: DREAlentejo (2010.

Em 2008, foi promulgada a Portaria ํㅡㄴ 230/2008, de 7 de Março $^{6}$, actual enquadramento legal para a oferta EFA, complementada, recentemente, pela Portaria ํㅜ 711/2010, de 17 de Agosto.

\section{As especificidades do modelo de formação/estrutura curricular dos Cursos}

\section{EFA}

\footnotetext{
${ }^{6}$ Esta portaria procede à introdução de ajustamentos no regime jurídico dos Cursos EFA e à regulamentação das formações modulares, integrando no mesmo instrumento jurídico, as duas modalidades de formação fundamentais para a qualificação dos adultos.
} 
O modelo de formação dos cursos EFA organiza-se de acordo com algumas especificidades, que o distinguem das ofertas formativas para jovens e das ofertas formativas para a população adulta, até então existentes, nomeadamente as modalidades decorrentes do Ensino Recorrente. Passamos, a enumerar, de seguida, 10 pontos que, na nossa opinião, constituem especificidades desta oferta formativa:

(i) Possibilidade de realização de percursos flexíveis e tipificados de formação definidos a partir de processos de reconhecimento, validação e certificação de competências, previamente adquiridas pelos adultos por via formal, não formal e informal e/ou de acordo com as habilitações de acesso iniciais. Privilegia-se a diferenciação de percursos formativos e a sua contextualização no meio social, económico e profissional dos formandos;

(ii) Desenvolvimento de percursos formativos de forma articulada, integrando uma componente de Formação de Base (FB) e uma outra de Formação Tecnológica (FT), ou apenas uma destas;

(iii) A sua estrutura curricular assenta numa base modular. Os cursos são organizados através de áreas de Competências-Chave (ACC), organizadas por Unidades de Formação de Curta Duração (UFCD), constantes do Catálogo Nacional de Qualificações (CNQ) e por um módulo de carácter mais instrumental que, no nível básico, possui a designação de Aprender com Autonomia (AA), com a carga horária de 40 horas e, no nível secundário, é designado por Área de Portefólio Reflexivo de Aprendizagens (PRA), com uma carga horária variável, em função do percurso formativo;

No nível básico, há 4 áreas de Competências-Chave, integradas na Formação de Base: Linguagem e Comunicação (LC), Matemática para a Vida (MV), Tecnologias de

Informação e Comunicação (TIC) e Cidadania e Empregabilidade (CE), conforme se observa na Figura 1:

Figura 1. Desenho Curricular dos Cursos EFA de nível básico 


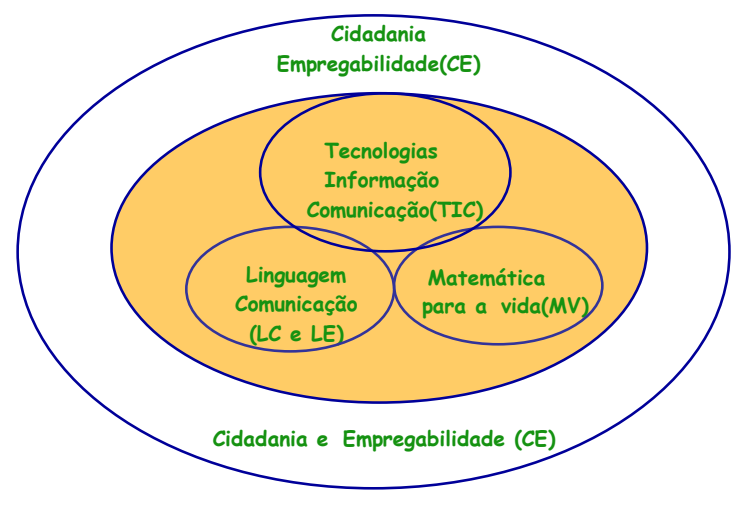

Fonte: Alonso et al (2001).

No nível secundário, as áreas de competências-chave, integradas na Formação de Base (FB) são 3: Cidadania e Empregabilidade (CP), Cultura, Língua e Comunicação (CLC), e Sociedade, Tecnologia e Ciência (STC), conforme se pode observar na Figura 2:

Figura 2. Desenho Curricular dos Cursos EFA de nível secundário

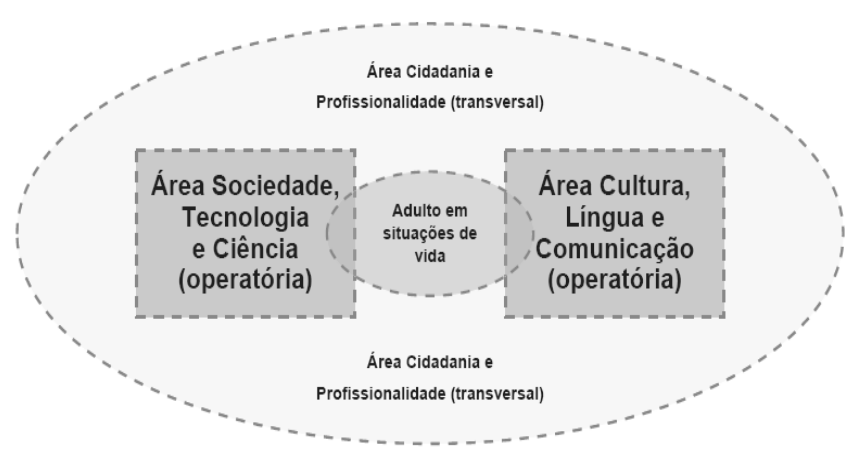

Fonte: Gomes et al (2006).

Quer no nível básico, quer no nível secundário, a Formação Tecnológica, quando existente, varia em função do Itinerário Profissional seleccionado e, nesse caso, o curso EFA terá, também, no seu elenco curricular, uma carga horária para a Formação Prática em Contexto de Trabalho (no mínimo de 120 horas, no nível básico e de 210 horas no nível secundário).

(iv) Desenvolvimento da formação centrada em processos reflexivos e de aquisição de saberes e competências que facilitem e promovam as aprendizagens (construção de um Portefólio Reflexivo de Aprendizagens); 
(v) Orientam-se através de Referenciais de Competências-Chave. Actualmente, os referenciais dos cursos EFA estão inseridos no Catálogo Nacional de Qualificações, conforme determina o actual regime jurídico desta oferta: “...simultaneamente, procede-se a uma profunda integração das ofertas de educação e formação, no sentido da estruturação de um sistema nacional de qualificações, baseado no Catálogo Nacional de Qualificações, no qual se inscrevemos cursos EFA, enquanto modalidade de formação de dupla certificação especificamente dirigida à população adulta." (preâmbulo da Portaria n.․․ 230/2008, de 7 de Março).

(vii) Articulação que existe entre a actividade dos Centros Novas Oportunidades, no seu eixo de encaminhamento de adultos, para as ofertas formativas externas aos próprios Centros. Entre as várias ofertas, os adultos podem ser encaminhados para os cursos EFA.

(viii) A flexibilidade horária, pois destinando-se a adultos com idade igual ou superior a 18 anos, à data do início da formação, podem ser ministrados em regime laboral ou pós-laboral, em função das disponibilidades e das exigências profissionais, com possibilidade de concretizarem percursos (de nível básico e secundário) de componente escolar, tecnológica ou de dupla certificação, e dessa forma, obterem, uma certificação escolar e/ou tecnológica.

(ix) Valorização da oferta EFA, sob o ponto de vista do acesso a formação financiada, através do Eixo 2, do Programa Operacional Potencial Humano (POPH), inserido no Quadro Estratégico Nacional (QREN). ${ }^{7}$

(x) Diversidade de tipologia de entidades promotoras dos cursos EFA (artigo 3.․, Portaria n. $.230 / 2008$, de 7 de Março), designadamente, entidades de natureza pública, privada ou cooperativa, como os estabelecimentos de ensino, centros de formação profissional, autarquias, empresas ou associações empresariais, sindicatos e associações de âmbito local, regional ou nacional. Apenas as entidades acreditadas pela Direcção-Geral do Emprego e das Relações de Trabalho (DGERT), podem ser formadoras de cursos EFA.

No que respeita aos processos de certificação dos formandos (artigo 34. , Portaria n.. 230/2008, de 7 de Março), nem todas as entidades formadoras de cursos EFA possuem competência certificadora. Apenas os estabelecimentos de ensino público e estabelecimentos de ensino particular ou cooperativo, com autonomia pedagógica, incluindo as escolas profissionais ou centros de formação de gestão directa ou protocolar tem essa competência. As entidades formadoras sem competência certificadora deverão celebrar um protocolo com uma das entidades acima referidas, que desenvolvam cursos EFA, para a homologação dos seus certificados e diplomas.

\footnotetext{
${ }^{7}$ Eixo Prioritário 2 - Adaptabilidade e Aprendizagem ao Longo da Vida (Tipologia de Intervenção 2.2 - Cursos de Educação e Formação de Adultos.
} 
As entidades interessadas em desenvolver esta oferta submetem as candidaturas EFA numa plataforma de gestão das ofertas dirigidas a adultos, denominada SIGO - Sistema de Informação de gestão da Oferta, através da qual as estruturas regionais competentes autorizam e monitorizam a oferta.

A Iniciativa Novas Oportunidades, que existe desde 2005, preparou um segundo ciclo de actividade, cujo lema é Qualificar os Portugueses: Uma Prioridade no Presente e no Futuro, o qual decorrerá entre 2011 e 2015, numa aposta significativa no princípio e perspectiva de aprendizagem ao longo da vida (ALV), tal como afirmado no Memorando sobre a Aprendizagem ao Longo da Vida (Comissão Europeia, 2000). Os cursos EFA continuam a ser uma das modalidades de educação e formação inscrita e valorizada no âmbito dessa iniciativa, apostando-se em percursos de dupla certificação que possam dotar as pessoas adultas de mais e melhores ferramentas para fazer face ao mercado de trabalho actual e às mudanças tecnológicas, sociais e económicas que exigem cidadãos, mais competente e em constante actualização dos seus conhecimentos e aprendizagens.

\section{Referências Bibliográficas}

ALONSO, Luísa et al (2001). Referencial de Competências-Chave - Educação e Formação de Adultos. Lisboa: ANEFA.

ANEFA (2002). Relatório Nacional sobre os Cursos de Educação e Formação de Adultos "Em observação" 2000/2001. Lisboa: ANEFA.

COMISSÃO EUROPEIA (2000). Memorando sobre Aprendizagem ao Longo da Vida. Bruxelas.

DREAlentejo (2010). Documentos vários.

GOMES, Maria do Carmo et al (2006). Referencial de Competências-Chave para a Educação e Formação de Adultos - Nível Secundário. Lisboa: ME/DGFV.

NICO, Lurdes (2009). Avaliação do(s) Impacto(s) do Processo de Reconhecimento, Validação e Certificação de Competências (RVCC), no Alentejo (período 2001-2005) [Tese apresentada à Universidade de Évora tendo em vista a obtenção do Grau de Doutor em Ciências da Educação]. Évora: Universidade de Évora (policopiada).

TRIGO, Márcia (2001). "Acções de Curta Duração". In Revista Saber Mais. N. 11.Lisboa: ANEFA.p.27. 